Jurnal Pendidikan Sosial Keberagaman

Print-ISSN 2355-4622 Online-ISSN 2622-9021

Vol. 6, No. 1, Oktober-Maret 2019, hh. 46-56

https://juridiksiam.unram.ac.id/index.php/juridiksiam

\title{
ASPEK PENDIDIKAN NILAI PANCASILA DALAM PERKAWINAN ADAT MBOJO (Studi Di Desa Soro Kecamatan Kempo Kabupaten Dompu)
}

\author{
Suci Indrawati ${ }^{1}$, Edi Herianto ${ }^{2}$, Dahlan $^{3}$ \\ ${ }^{1}$ Mahasiswa prodi PPKn, ${ }^{23}$ Dosen Jurusan Pendidikan IPS \\ Fakultas Keguruan dan Ilmu Pendidikan Universitas Mataram \\ Email: edyherianto.fkipunram $\overline{2}$ gmail.com
}

\begin{abstract}
Abstrak
Dalam rangka untuk melestarikan pancasila dalam generasi perkenal dan perluasan pancasila harus dirangkaikan dengan adat dan budaya yang melekat pada masyrakat tersebut, salah satu cara untuk mempertahankan nilai pancasila dengan memandang kegitan ritual alat harus menggunakan prespektif pancasila dalam upaya pelestarian budaya dan pancasila.Atas dasar kondisi tersebut penulis tertarik melakukan penelitian skripsi dengan judul" Aspek Pendidikan Nilai Pancasila Dalam Perkawianan Adat Mbojo di Dompu ( Studi Di Desa Soro Kecematan Kempo Kab.Dompu)" dengan tujuan penelitian ini adalah untuk mengetahui aspek pendidikan nilai pancasila dalam pelaksanaan tradisi perkawinan adatMbojo, memperoleh nilai nilai pendidikan pancasila dalam tradisi perkawainan adat Mbozo(Studi di Desa soro Kecamatan Kempo Kabupaten Dompu). Metode penelitian yang digunakan dalam penelitian ini adalah penelitain kualitatif, dengan teknik pengumpulan data mengunakan teknik observasi, wawancara, studi dokumentasi. Teknik analisis data yang dgunakan adalah teknik reduksi data, penyajian data, penarikan kesimpulan.Adapun hasil dari penelitian ini yaitu bentuk bentuk dari tradisi perkawinan adat Dompu, anatara lain: Dou Sodi (pinangan), Ngge Nduru (tinggal Bersama di rumah mertua), penati (melamar), wi,i Ngahi atau simpan tanya, mbolo weki, wa, a coi atau antar mahar, kapanca (pacar), akad nikah dan Resepsi atau jambuta. Nilai nilai pancasila yang terkandung dalam perkawinan adat Mbojo Dompu antara lain sebagai berikut: gotong royong, selalu hidup berdampingan saling menghargai dan menghormati, suka menolong dan menghargai budaya leluhur. Dari setiap sesi dan prosesi rangkaian kegiatan perkawianan adat masyarakat desa Soro mengadung semua unsur nilai nilai pancasila yang terdiri dari nilai ketuharan, kemanusiaan yang adil dan beradap, persatuan indonesia, permusyawatan perwakilan yang di pimpin oleh hikmat kebijaksanan serta keadilan bagi seluruh rakyat indonesia.
\end{abstract}

Kata Kunci : Pendidikan Pancasila Dalam Perkawinan Adat Mbojo

\begin{abstract}
Abstrack
In order to preserve the Pancasila in the familiar generation and expansion of the Pancasila, it must be coupled with the customs and culture inherent in the community. One way to maintain the Pancasila values by looking at the practices of traditional ituals must be to use the Pancasila perspective in preserving culture and Pancasila.On the basis of these conditions the author is interested in conducting thesis research with the title "Aspects of Pancasila Value Education in Mbojo Traditional Marriage in Dompu (Study in Soro Kecamatan Kempo Village, Dompu Regency)" with the aim of this study Mbojo obtained the value of Pancasila education in the traditional Mbozo marriage tradition (Study in the soro village of Kempo District, Dompu Regency). The research method used in this study is qualitative research, with data collection techniques using observation, interviews, documentation studies. Data analysis techniques used are data reduction techniques, data presentation, conclusion drawing. The results of this study are the form of the traditional marriage tradition of Dompu, among others: Dou Sodi (pinangan), Ngge Nduru (living together at
\end{abstract}


home-in-law), penati (applying), wi, i Ngahi or save asking, mbolo weki, wa , a coi or inter-dowry, kapanca (girlfriend), marriage contract and reception or jambuta. The Pancasila values contained in Mbojo Dompu's traditional marriage include the following: mutual cooperation, always living side by side with mutual respect and respect, helping and respecting ancestral culture. From each session and procession the series of traditional marriages activities of the Soro village community contain all elements of the Pancasila values that consist of divine values, just and humanitarian humanity, Indonesian unity, representative meetings led by wisdom of wisdom and justice for all Indonesian people.

\section{Keywords: Pancasila Education in Mbojo Indigenous Marriage}

\section{PENDAHULUAN}

Sistem Pendidikan Nasional sebagai pendidikan nonformal yang diperkaya dengan pendidikan nilainilai pancasila dalam pembentukan kepribadian yang berakhlak mulia, berjiwa patriotik, taat hukum, disiplin, menjunjung tinggi nilai-nilai luhur bangsa, dan memiliki kecakapan hidup. Salah satu tawaran yang coba di munculkan dalam pengembangan nilai-nilai pancasila adalah dengan cara memberikan pemahaman bagi masyarakat secara luas dan peserta didik, bahwa dalam pelaksanan adat dan tradisi terkandung nilai nilai pendidikan pancasila di dalamnya. Seperti yang di kemukan oleh beberapa ahli bahwa begitu pentingnya nilai-nilai pancasila yang terkandung dalam tradisi kita sehari hari.

Adisusilo (2013: 56-57) menyebutkan definisi nilai sebagai kualitas suatu hal yang menjadikan hal itu disukai, diinginkan, dikejar, dihargai, berguna dan dapat membuat orang yang menghayatinya menjadi bermartabat. Nilai akan selalu berhubungan dengan kebaikan, kebajikan, dan keluhuran budi serta akan menjadi sesuatu yang dihargai dan dijunjung tinggi serta dikejar oleh seseorang sehingga ia merasakan adanya suatu kepuasan, ia menjadi manusia yang sebenarnya. Sejalan dengan dua pendapat di atas, pendapat Sastrapratedja yang dikutip oleh Subiyantoro (2013: 82) menjelaskan bahwa nilai adalah sesuatu yang dianggap positif, dihargai, diagungkan, dipelihara, dihormati, dan membuat orang bangga.

Masyarakat Dompu memiliki tradisi adat istiadat secara turun temurun.seiring dengan perkembangan zaman, kedudukan budaya dalam pola kemasyrakatan memiliki sifat dinamis, berkembang dari masa ke masa dan mengalami perubahan. Namun, perubahan yang bersifat pembaharuan ini, tidak berpengaruh dalam eksistensi nilai-nilai budaya.Nilai kebudayaan yang di maksud memiliki kandungan-kandungan makna yang menuju pada tatanan kehidupan. Tradisi pernikahan adat Dompu di sini memiliki kandungan makna yang bernilai, misalnya dalam tata cara pelaksanaanya. Pada tata cara pelaksanaanya setiap adat upacara pernikahan adat Dompu.

Perkawinan adat merupakan tradisi turun-temurun yang masih tetap dijaga oleh masyarakat di Desa Soro Kecematan Kempo Kabupaten Dompu. Terdapat rangkaian proses atau ritual pelaksanaan perkawinan yang harus di lalui oleh seseorang dalam melaksanakan perkawinan, mulai dari mbaju, Mbolo Keluarga, Mblo Weki, wa, a co,i, peta kapanca (mengumpulkan padi, rapat keluarga, rapat kampong, antar mahar, dan prosesi panca pengantin). 
Vol. 6 No. 1, Oktober-Maret 2019, hh. 46-56

Dalam rangka untuk melestarikan pancasila dalam generasi perkenal dan perluasan pancasila harus dirangkaikan dengan adat dan budaya yang melekat pada masyrakat tersebut, salah sau cara untuk mempertahankan nilai pancasila dengan memandang kegitan ritual adat harus menggunakan prespektif pancasila dalam upaya pelestarian budaya dan pancasila.

Rumusan masalah dalam penelitaian ini yaitu :Bagaimanakah pelaksanaan tradisi perkawinan adat masyarakat Soro Kecamatan Kempo kabupaten Dompu dalam prespektif Pendidikan nilai dan Pancasila, Bagaimanakah kondisi sosial budaya masyarakat Desa Soro Kec. Kempo Kabupaten Domp, dan Bagaimanakah bentuk bentuk nilai pendidikan pancasila yang terkandung dalam tradisi terkawinan adat masyrakat Dompu khususnya di Desa Soro Kecematan Kempo Kabupaten Dompu.

\section{METODE PENELITIAN}

Pendekatan yang digunakan dalam penelitian ini adalah pendekatan kualitatifdengan jenis penelitian bersifat deskriptif-analitik yang berarti interprestasi terhadap isi dibuat dan disusun secara sistematik/menyeluruh dan sistematis. Adapun sumber data yang dapat dipergunakan dalam penelitian ini didasari data sumber yaitu: Sumber data primer dan Sumber data skunder,Adapun teknik pengumpulan data adalah sebagai berikut: Observasi Partisipatif, Wawancara dan Studi Dokumentasi. Teknik Analisis Data adalah proses mengorganisasikan dengan mengurutkan data ke dalam pola, kategorisasi, dan satuan uraian dasar sehingga dapat ditemukan tema dan hipotesa kerja seperti yang disarankan data. Data yang telah diorganisasi kedalam suatu pola dan membuat kategorinya, maka data dapat diolah dengan menggunakan analisis data model Milles dan Hubberman, yaitu: Reduksi DataReduksi data bertujuan untuk memudahkan membuat kesimpulan data yang diperoleh selama pelaksanaan penelitian, Penyajian Data merupakan sekumpulan informasi tersusun yang memberi kemungkinan adanya penarikan kesimpulan dan pengambilan tindakandan Penarikan Kesimpulan. Teknik Penjaminan Keabsahan Data yang terdiri dari: Kredibilitas (credi bility), Keteralihan (transferability), Ketergantungan (dependability), Ketegasan (confirmability).

\section{HASIL DAN PEMBAHASAN}

\section{Proses Pelaksanaan Tradisi Perkawinan Adat Dompu Dalam Prespektif Pendidikan Nilai dan Pancasila.}

Berdasarkan hasil wawancara dengan tokoh masyarakat dan tokoh agama di Desa Soro Kecematan Kempo dan Kabupaten Dompu, proses pelaksanaan adat upacara pernikahan di Desa Soro Kcematan Kempo Kabupaten Dompu antara lain sebagai berikut:Dou Sodi (pinangan), Ngge'e nuru (tinggal bersama di rumah calon mertua), Panati (melamar), Wii nggahi (menitipkan ikatan antara kebelah pihak), Mbolo weki atau musyawarah masing-masing pihak yang bersangkutan, Wa'a coi atau antar Mahar, Kapanca/ Pacar, Akad Nikah., Resepsi/ jambuta/ tekarne'e. 
Nilai-nilai pendidikan pancasila yang terdapat dalam prosesi pernikahan adalah nilai yang berdasarkan pancasila yang terdapat pada prosesi pernikahan di Desa Soro Kecamatan Kempo Kabupaten Dompu Propinsi Nusa Tenggara Barat.Nilai yang mengandung unsur-unsur pendidikan pancasila seperti halnya pada acara yang dilakukan terlihat pada prosesi dan sesinya yang di siapakan dalam bentuk gotong royong dan memandang nilai-nilai spritula kepercayaan seperti nilai Ketuhanan misalkan dalam pemilihan waktu dan hari karena memakai tanggal dan bulan sesuai dengan ajaran Islam, pembacaan kitab suci Al-quran, ijab kabul, salawat badar seperti acara khatam al-Quran maupun acara akad nikah yang dilakukan secara Islamdan mengedepankan nilai-nilai ketuhanan. Nilai pendidikan pancasila yang tertuang dalam prosesi pernikahan adat masayarakat kempo selain dari nilai ketuhanan yang maha esa yaitu nilai musyawarah mufakatbersama dalam menentukan segala macam rangkain prosesi pernikahan, seperti penentuan hari, dimulainya rangkain acara dan sampai pada prosesi puncak kegiatanya.

\section{Bentuk-bentuk Kondisi Sosial Budaya Desa Soro Kecamatan Kempo Kabupaten Dompu}

Budaya lokal adalah suatu budaya yang berkembang di daerah-daerah dan merupakan milik suku bangsa nusantara.Bangsa Indonesia di kenal sebagai bangsa yang multikultural dalam suku bangsa dan budaya. Sedangkan budaya yang digunakan atau yang dianut oleh masyarakat Desa Soro Kempo yaitu mengakularasikan antara budaya lokal dan budaya islam, yang dimana budaya islam mulai muncul pada abat ke-17 di tanah dompu dan pulau Sumbawa khususnya. Percampuran budaya lokal dengan budaya Islam sangat mempengaruhi kehidupan sosial dalam masyarakat.Di dalam masyarakat yang berada di Desa Soro Kecematan Kempo Kabuapten Dompu terjadi percampuran budaya lokal dalam adat pernikahan.Adat pernikahan yang ada pada masyarakat Desa Soro Kecematan Kempo Kabupaten Dompu sudah tercampur oleh budaya Islam baik dari segi perencanaan, pelaksanaan dan sebagainya.Di dalam kehidupan masyarakat Desa Soro adat yang lama tidak bisa dan dihilangkan begitu saja walaupun Islam sudah masuk dan berkembang.Percampuran budaya lokal dengan budaya Islam (akulturasi) dalam masyarakat Desa Soro tidak begitu banyak memiliki hambatan.Budaya lokal yang masih di pertahankan sampai sekarang ini dalam adat pernikahan terlihat dari ketika acara pernikahan itu maka wajib bagi masyarakat untuk melakukan berbagai tahapan-tahapan dalam suatu acara pernikahan tersebut.

"Bentuk-bentuk budaya lokal dalam adat pernikahan di Desa Soro terletak pada pemilihan jodoh.Memilih jodoh adalah suatu hal yang amat penting yang harus dilakukan oleh seseorang sebelum melangsungkan perkawinan. Karena hal itu dianggap suatu yang penting yang menjadi bagian dari rangkaian pelaksanaan perkawinan, khitbah atau lamaran dilakukan oleh pihak sampela mone atau pihak laki-laki melalui seorang juru lamaratau ompu panati dan kedua orang tua laki-laki,wii nggahi dilakukan beberapa hari setelah lamaran diterima. Upacara ini biasanya dilakukan pada malam hari bertempat dirumah orang tua si gadis.”(Wawancara dengan bapak H. Ntara pada tanggal 05-08 Agustus 2018). 
Persentuhan budaya Islam dengan budaya lokal sangat berpengaruh dalam kehidupan bermasyarakat. Sebagai medan budaya yang diwarnai ataupun dengan Islam pada akhirnya berorientasi secara konseptual untuk memperoleh berkas sebagai suatu yang sakral Islam yang bernuansa lokalitas tersebut hadir melalui tafsiran agen-agen sosial yang secara aktif berkolaborasi dengan masyarakat luas dalam kerangka mewujudkan Islam yang bercorak khas, yaitu Islam dan pancasila yang begitu menghargai terhadap adat di nilai absah/sahih.

\section{Bentuk Nilai Pendidikan Pancasila Yang Terkandung Dalam Perkawinan Adat Masyarakat Dompu Khususnya Di Desa Soro Kecematan Kempo Kabupaten Dompu.}

Adapun titik temu nilai pendidikan pancasila dengan tradisi lokal ataupun budaya masyarakat Soro dalam perkawinan adat masyarakat Soro adalah pada saat acara antar mahar, musyawara keluarga, acara kapanca atau pacar di sini terlihat betapa kentalnya nilai nilai pancasila yang terkandung di dalamnya yang di dampingi dengan tradisi lokal saling melengkapi satu sama lain. Sehingga terlihat sangat sakral. Seperti ungkapan informan yang telah saya wawancarai:

“Adapun nilai-nilai pendidikan pancasila yang tertuang dalam upacara perkawinan adat masyarakat Desa Soro Kecematan Kempo Kabupaten Dompu terlihat pada acara wa'a coi atau antar mahar, kapanca atau pacar, resepsi/ jambuta/ tekarane'e di mana dalam acara tersebut percampuran nilai-nilai pancasila terhadap budaya lokal terutama dalam acara kapanca atau pacar misalnya dalam acara ini adanya dalam persiapan masyarakat atau warga berbondong bondong gotong royong, saling bantu membantu, bahu membahu menyukseskan acara dan rangkaian acara perkawinan adat di Desa Soro, dan di tuangkannya nilai nilai ketuhanan seperti yang tertera pada sila pertama pancasila. Dalam hal ini warga masyarakat desa soro menganut agama islam, sehingga nilai nilai islam dalam prosesi pernikahan pun di gunakan misalakan dzikir dan meletakkan daun pacar di dalam tangga pengantin perempuan dan suasananya sakral. Dan pada saat acara resepsi/ jambuta/ tekarane'e nilai ketuhanan dalam acara ini terletak pada rangakain acaranya mulai pembukaan sampai selesai misalnya ada bacaan doa, lagu-lagu yang di bawakan oleh para undangan ada lagu daerah dan pentas budaya dan lain lain” . (Wawancara dengan bapak Ismal Zamaluddin pada tanggal 02-04 Agustus 2018).

\section{PEMBAHASAN}

Proses Pelaksanaan Tradisi Perkawinan Adat Mbojo di Dompu Melalui Tahap Tahap Sebagai Berikut ini:

Berdasarkan hasil wawancara dengan tokoh masyarakat dan tokoh agama di Desa Soro Kecematan Kempo dan Kabupaten Dompu, proses pelaksanan adat upacara pernikahan di Desa Soro Kcematan Kempo Kabupaten Dompu antara lain sebagai berikut:

1. Dou Sodi (pinangan) 
Acara melamar/meminang dalam bahasa daerah disebut panati(Meminang). Orang yang diutus untuk melakukan pinangan yang disebut ompu panati.Bila pinangan itu di terima, resmilah kedua orang remaja berada dalam ikatan pacaran satu dengan yang lain disebut Dou sodi (douartinya Orang, sodi artinya tanya, maksudnya orang yang sudah di tanya isi hatinya dan sepakat untuk dinikahkan).

2. Ngge'e nuru (tinggal bersama di rumah calon mertua)

Ngge'e nuru maksudnya calon suami tinggal bersama di rumah calon mertua.Ngge'e artinya tinggal, Nuru artinya ikut.Pria sudah di terima lamaranya. Bila kedua belah pihak menghendaki, sang pria di perkenankan tinggal bersama calon mertua di rumah calon mertuanya tersebut. Dia akan menanti bulan baik dan hari baik untuk melaksanakan upacara pernikahan.

3. Panati (melamar)

Tradisi Dompu, Penati menjadi pintu gerbang menuju ke jenjang pernikahan. Panati adalah melamaran atau meminang perempuan.Panati di awali dengan datangnya utusan pihak laki-laki ke orang tua perempuan. Utusan ini untuk menanyakan apakah sang gadis sudah memiliki kumbang atau calon suami. Bila memperoleh jawaban bahwa sang perempuan berstatus bebas, kembali di lakukan pendekatan untuk mengetahui apakah perempuan itu dapat di lamar jika lamaran itu di terima oleh pihak perempuan, pria melakukan apa yang disebut Wi'i ngahi. Pada hari yang di tetapkan, pertunangan di resmikan dalam upacara Pita nggahi artinya lamaran sekaligus pertunangan.

4. Wii nggahi (simpan tanya)

Wii nggahi atau sudah di terimah lamaranya. Apabila lamaran sudah diterimah oleh orang tua dan keluarga si gadis, maka semua keluarga si pemuda akan legah termasuk juga ompu panati. Pemuda dan si gadis berada dalam saat bertunangan resmi disebut sodi angi, kini di resmikan dalam suatu upacara yang disebut wii nggahi dan di Dompu lao karuu ra nggahi, artinya pergi melihat kembali si gadis dengan membawa jumlah barang pemberian sebagai tanda pertunangan yang resmi.

5. Mbolo weki atau musyawarah masing-masing pihak yang bersangkutan

Mbolo weki yang dalam bahasa Indonesia berarti kerja, kegiatan dalam acara perkawinan. Oleh karena upacara tersebut menyangkut kerabat dari pihak laki-laki maupun pihak perempuan untuk itu perlu ditentukan waktu pelaksaannya dengan diikut sertakan pihak-pihak yang berkepentingan.

6. Wa'a coi atau antar Mahar

Wa'a coi artinya upacara pengantar barang dan uang yang menjadi maskawin dalam perkawinan. Upacara wa'a coi selalu dihadiri oleh wakil-wakil dari calon pengantin putra dan wakil dari pihak calon pengantin putri dengan disaksikan oleh imam, masyarakat, kepala desa dan pemuka masyarakat lainya serta para anggota kerabat kedua belah pihak. Acara wa'a coi biasanya dilakukan pada pagi hari atau sore jam 16.00, tergantung jauh dekatnya rumah orang tua calon pengantin 
putri.Demikian pula besar anggota rombongan wa'a coi sangat tergantung dari jumlah barang yang dibawa sebagai maskawin, sesuai dengan persetujuan kedua belah pihak sebelumnya.

7. Kapanca/ Pacar

Kapanca yang maksud dengan malam kapanca tersebut ialah suatu acara di malam hari menjelang akad nikah besok harinya. Malam kapanca ini biasanya di mulai pada jam 20.00 malam selesai sholat isya sampai selesai Pada malam hari sebelum akad nikah di kediaman calon mempelai wanita akan melaksanakan upacara malam kapanca atau pemakaian daun pacar, dengan mamulung daun pacar, para ibu-ibu secara bergantian memasang daun pacar atau pemakaian daun pacar tersebut tidak hanya di kuku tapi juga di telapak tangan calon mempelai wanita dan harus berjumlah ganjil tujuh atau sembilan orang.

8. Akad Nikah.

Dalam acara akad nikah ini yang berperan adalah panitia seksi perkawinan dimana acaraacaranya diatur sebagai berikut : a) Pembukaan oleh protokol; b) Pembacaan ayat-ayat suci Al-quran; c) Dialog dari masing-masing kedua wakil penganting yang biasanya disaat itulahdiperlihatkan atau diserahkan mahar atau coi dengan hasil pembicaraan semulayang dibawah oleh pihak pengantin lakilaki; d) Sebagian Wali menyerahkan kuasa penuh kepada penghulu (ulama) ataubiasanya Wali Sendiri yang akan menikahkan anak perempuannya. e) Akad nikah dilangsungkan oleh penghulu yang didampingi oleh sekurang-kurangnyaoleh kedua orang saksi atau biasanya ditunjuk oleh masingmasingpemerintah setempat kepala lingkungan atau Imam lingkungan dengan terlebihdahulu diadakan pembinaan kepada pihak pengantin laki-laki.

9. Resepsi/ jambuta/ tekarne'e

Biasanya dengan adanya acara resepsi/jambuta/tekarne'e ini sangat ditunggu-tunggu oleh masyarakat setempat.Dan disini pula puncat suatu acara pernikahan. Kemudian acara ini biasanya masyarakat setempat saling membantu satu sama lain bergotong royong mulai dari acara lamaran sampai acara resepsi/ jambuta/ tekarne'e ini. Tampak sangat resmi, karena para undangan pria menggunakan pakaian rapi wanita-wanita berbaju kebaya dan ada juga menggunakan gaun.Sedangkan kedua pengantin menggunakan pakaian adat suku Dompu atau gaun pengantin.

\section{Nilai-Nilai Pancasila Yang Terkandung Dalam Perkawinan Adat Mbojo Dompu}

Dalam prespektif lain dalam tulisan skripsi ini memandang juga bahwa nilai nilai yang terkandung dalam nilai nilai pancasila adalah sebagai berikut: 
a) Nilai Ketuhanan Yang Maha Esa

Nilai ketuhanan dalam perkawinan Adat Dompunampak dalam proses pelaksanaan berikut ini yaitu :

\section{Peta Kapanca (menempelkan daun pancar)}

Nilai relijiusitas yang tertera dalam prosesi peta kapancaa ini misalkan di tandai dengan sholawat Nabi dan membacakan ayat ayat suci Al Quraan, jikiran dan Do,a selamat dalam prpsesi ini.

\section{Resepsi dan Izap Kabul}

Dalam prosesi izab kabul dan resepsi yang di lakukan dalam acara perkawinan adat Dompu di dalamnya terdapat nilai agama misalkan dalam mebaca ayat suci alquran, tausiah pengatin oleh ustad, dan pembacaan ayat-ayatalquraan dalam rangkain kegiatan pernikahan.

\section{b) Nilai Kemanusiaan Yang Adil Dan Beradab}

Nilai-nilai yang terkandung dalam perkawinan adat Dompu memiliki kesamaan dengan nilainilai yang terkandung dalam sila kedua. Nilai-nilai tersebut nampak dalam proses pelaksanaan berikut ini yaitu hampir semua rakyan kegiatan perkawinan adat dompu khusunya desa soro mengadung nilai kemanusiaan yang adil dan beradap, maksudnya adalah saling mentu dan lain lain.

\section{c) Nilai persatuan Indonesia}

Nilai-nilai yang terkandung dalam perkawinan adat dompu memiliki kesamaan dengan nilainilai yang terkandung dalam sila ketiga. Nilai-nilai tersebut nampak dalam proses pelaksanaan berikut ini yaitu :

\section{Mbolo Weki (Musyawara Mufakat)}

Mbolo Wekimemiliki banyak nilai-nilai yang terkandung didalamnya, salah satunya adalah nilai persatuan yang ditunjukkan dalam sikap saling tolong menolong, dan melaksanakan tradisi adat Mbojo.

\section{Peta Kapanca}

Peta kapanca memiliki banyak nilai-nilai yang terkandung di dalamnya. Sala satunya nilai persatuan yang terkandung dalam sila ketiga. Nilai ini dapat dilihat pada saat semua orang datang menyaksikan dan melihat bahwa orang orang dan masyarakat akan menyaksikan bahwa anak gadis dari salah satu warga akan segera di pinang dan akan mengaakhiri masa lajangnya, dan kelompok masyarakat, tua muda dan laki akan bahu menbahu dalam mempersiapknya.

\section{Resepsi jambuta}

Dalam tradis resepsi jambuta dalam pernikahan adat mbojo dompu, terdapat banyak nilainilai yang terkandung didalamnya. Salah satunya adalah nilai persatuan yang nampak dari antusiasnya masyarakat untuk ikut melaksankan resespsi dan datang meberikan ucapan selamat 
dengan di tandai dengan pemberian bingkisan kepada pengantin dan jabat salam yang di berikan warga dan kerabat ke mempelai dan keluarga dnegan harapan meneberikan doa restu.

d) Nilaikerakyatan yang dipimpin oleh hikmat kebijaksanaan dalampermusyawaratan/perwakilan.

Nilai-nilai yang terkandung dalam proses perkawinan adat dompu dan mbojo adalah memiliki kesamaan dengan nilai-nilai yang terkandung dalam sila keempat. Nilai-nilai tersebut nampak dalam proses pelaksanaan berikut ini yaitu :

1. Sodi Angi (simpan tanya)

Dalam penjabaran diatas, sudah dijelaskan bahwa nilai yang terkandung alam sila keempat adalah musyawarah untuk mencapai mufakat.

\section{Dou sodi (pinangan)}

Upacara melamar/meminang dalam bahasa daerah disebut panati.Orang yang diutus untuk melakukan pinangan yang disebut ompu panati.Bila pinangan itu di terima, resmilah kedua orang remaja berada dalam ikatan pacaran satu dengan yang lain disebut Dou sodi (douartinya Orang, sodi artinya tanya, maksudnya orang yang sudah di tanya isi hatinya dan sepakat untuk dinikahkan).

3. Mbolo weki (musyawarah mufakat)

Mbolo weki yang dalam bahasa Indonesia berarti kerja, kegiatan dalam upacara perkawinan. Oleh karena upacara tersebut menyangkut kerabat dari pihak laki-laki maupun pihak perempuan untuk itu perlu ditentukan waktu pelaksaannya dengan diikut sertakan pihak-pihak yang berkepentingan.

\section{e) Nilai keadilan sosial bagi seluruh rakyat Indonesia}

Nilai keadilan yang terkandung didalamnya meliputi keadilan dalam berbagai bidang kehidupan yang sesuai dengan nilai-nilai yang terkandung dalam perkawinan adat Dompu dan Mbojo yakni terdapat pada saat prosesi mboloweki(musyawarah mufakat) yang dimana dalam mbolo weki disini akan di tentukan dan di persatukan seluruh masyarakt terutama keluarga kedua bela pihak mempelai dalam hal menentukan mahar yang seadil adilnya dan menentukan tanggal pernikahan dan lain lainya. Poin kedua yang mengandung nilai pancasila dalam sila kelima untuk tradisi perkawinan adat mbojo dan Dompu yaitu dalam acara jambuta resepsi dan acara peta kapanca, dalam rangkain acara perkawinan adat masyarakat Dompu khususnya masyarakat Soro bahwa dalam acara peta kapanca dan resepsi di situlah ruang dimana menyatukan seluruh lapisan masyarakat, mulai dari tua muda, kecil dan lain, lain. 


\section{PENUTUP}

\section{Kesimpulan}

Pelaksanaan rangkaian perkawinan adat masyarakat Desa Soro yang dimulai dari prosesi lamaran sampai dengan resepsi merupakan bagian dari kebudayaan. Tradisi perkawinan adat masyarat Desa Soro tidak bertentangan atau mengedepankan nilai nilai pancasilayaitu ketuhanan yang Maha Esa, Kemanusiaan yang adil dan beradap, persatuan Indonesia, kerakyatan yang di pimpin oleh hikmat kebijaksanaan dalam permusyawaratan perwakilan serta keadilan sosial bagi seluruh rakyat Indonesia. Dari bentuk-bentuk kondisi sosial budaya masyarakat Desa Soro dalam melaksanakan tradisi perkawinan adat Panati atau lamaranmengadung nilai sila pertama atau sila ketuhanan yang maha esa, wi'i ngahi(pinangan)mengandung nilai silakedua dan kempat, Mbolo wekimengadung nilai sila ke tiga dan ke empat, peta kapanca (panca) mengadung nilai pancasila sila pertama dan ke tiga, wa, a co,i (antar mahar)mengandung nilai pancasila sila ke tiga dan lima, akad nikah mengung nilai sila pertama, Resepsi jambuta tekarane,e mengadung nilai pancasila sila pertama dan sila ke tiga, sehingga menghasilkan pola kehidupan masyarakat yang memiliki keserasian fungsi yang saling mempengaruhi antara budaya lokal dengan nilai pendidikan pancasila.

\section{DAFTAR PUSTAKA}

Abdullah Sidik, SH., Hukum perkawinan Islam, Penerbit Tinta Jakarta.

Abdurrahman, 1978, Masalah-masalah Hukum Perkawinan Di Indonesia. Penerbit Alumni, Bandung. Agama. Jakarata: PT Raja Grafindi Persada, 2006.

Ani Sri Rahayu 2013, Pendidikan Pancasila \&Kewarganegaraan(PPKn), Jakarta: Bumi Aksara.

Arikunto suharsimin 2002, Prosedur penelitian suatu pendekatan praktek, Jakarta Rineka

Arsyad Umar ,dkk 2006., Pendidikan Kewarganegaraan untuk SD kelas IV, Jakarta: Erlangga.

Artati Agoes 2000, Kiat Sukses Menyelenggarakan Pesta Perkawinan Adat Jawa (Gaya Surakarta dan Yogyakarta), Jakarta: Gramedia Pustaka Utama.

Atlas, Indonesia Dunia Surabaya Cpta Media edisi 3.

Bustanuddin Agus, Agama Dalam Kehidupan Manusia: Pengantar Antropologi

Depertemen Pendidikan dan Kebudayaan, Adat Upacara Perkawinan Daerah Jawa, Jakarta : 1984.

Ficher 1989, Pengantar Antropologi Budaya Indonesia, Jakarta PT. Pembangunan.

Hilman Hadikusuma1992, Pengantar Ilmu Hukum Adat Indonesia, Bandung: Mandar Maju.

Jacobus Ranjabar 2006, Sistem Sosial Budaya Indonesia, Bogor: Ghalia Indonesia.

John Fiske 2004, Cultural and Communication Studies, Bandung: Jalasutra.

Kaelan, M.S 2010, Pendidikan Kewarganegaraan, Yogyakarta: Paradigma. 
Vol. 6 No. 1, Oktober-Maret 2019, hh. 46-56

M. Fachrir Rahman dan Nurmukmainah2011, Nikah Dompu antara Islam dan tradisi Mataram: Alam Tata Learning Institute.

M. Fachrir Rahman2008, Islam di Bima, Kajian Historis Tentang Proses Islamisasi dan Perkembangan sampai Masa Kesultanan Yogyakarta:Genta Press.

M. Mudandar Sselaeman 1992, Ilmu Sosial Dasar Teori dan Konsep Ilmu Sosial, Edisi Revisi, Cet. 6 Bandung: Eresco.

Muhammad Idrus Ramli, 2010.Membedah Bid'ah dan Tradisi dalam Perspektif Ahli Hadits dan Ulama Salaf, Surabaya: Khalista.

Mural Esten1992, Tradisi dan Modernitas dalam Sandiwara,Jakarta: Intermasa.

Piotr Sztompka 2011, Sosiologi Perubahan Sosial, Cetakan ke-06, Jakarta: Prenada

Purwadi 2005, Upacara Tradisional Jawa, Menggali Untaian Kearifan Lokal, Yogyakarta: Pustaka Pelajar.

Purwanto S.U 2007, Sosiologi Untuk Pemula, Yogyakarta: Media Wacana.

Ramdani Wahyu 2008, Ilmu Budaya Dasar, Bandung : Pustaka Setia.

Saadan Rahmany 1976, Semangat Muslim, Pengantar Antropologi, Jakarta.

Soerojo Wignjodipoero 1984, Pengantar dan Asas-asas Hukum Adat, Jakarta: Gunung Agung, cet. VII.

Sugiyono, 2005. Medelogi Penelitian Kualitatif dan Dan Kuantiatif Pendidikan,Jakarta.

Sutarjo Adisusilo, J.R 2013, Pembelajaran Nilai-Karakter, Jakarta: Rajawali Pers.

Sutoyo 2011, Pendidikan kewarganegaraan untuk perguruan tinggi, Yogyakarta: Graha Ilmu.

Syamsul Ma'arif, Dkk 2012, “School culture di madrasah dan sekolah”,Penelitian kolektif : Semarang.

Umar Tirtarahardja dan S. L. La Sulo 2005, Pengantar Pendidikan, Jakarta: Rineka Cipta.

Undang-undang No 1 tahun 1974 tentang Perkawinan (Lembaran Negara Republik Indonesia Tahun 1974 Nomor 1, Tambahan Lembaran Negara Republik Indonesia Nomor 3019)

Wahyu Ms, Wawasan Ilmu Sosial DasarSurabaya: Usaha Nasional, t,th,

Wasid, Dkk 2011, Menafsirkan Tradisi dan Modernitas; Ide-Ide Pembaharuan Islam, Surabaya: Pustaka Idea.

Wignjodipoere, Soerjono, 1988, Asas-asas Hukum Adat, Gunung Agung, Jakarta. 